\title{
Erratum to: Developing Mentoring Competency: Does a One Session Training Workshop Have Impact?
}

\author{
Chloe Lau $^{1} \cdot$ Jennifer Ford $^{1} \cdot$ Ryan J. Van Lieshout ${ }^{1} \cdot$ Karen Saperson $^{1}$ • \\ Meghan McConnell $^{1} \cdot$ Randi McCabe $^{1}$
}

Published online: 23 May 2016

(C) Academic Psychiatry 2016

Erratum to: Acad Psychiatry (2016)

DOI: 10.1007/s40596-016-0537-8

The legend description for Fig. 1 in the original version of the above article contained an error. The correct legend description should read as follows:

Fig. 1. Participants' increase in subscores across six mentoring competencies before and after the workshop (scale 1 to $7 ; 1$ not at all skilled, 4 moderately skilled, 7 extremely skilled; $n=36$ ). Error bars represent the standard error of the mean. *Represent $P \leq 0.003$

In addition, there is an error in the sentence containing the prepost scores describing Fig. 1 under the Quantitative Analyses section. The correct sentence should read: As illustrated in Fig. 1, there was a significant interaction between mentorship domain and pre-post scores $[F(5,155)=2.5, P<0.003)$.

The online version of the original article can be found at http//dx.doi.org/ 10.1007/s40596-016-0537-8.

Chloe Lau

clau263@uwo.ca

1 McMaster University, Hamilton, ON, Canada 